\title{
Correction to: The carbon pump supports high primary production in a shallow lake
}

\author{
Mikkel René Andersen ${ }^{1} \cdot$ Theis Kragh $^{2} \cdot$ Kenneth Thorø Martinsen ${ }^{2} \cdot$ Emil Kristensen $^{2} \cdot$ Kaj Sand-Jensen $^{2}$
}

Published online: 7 February 2019

(c) Springer Nature Switzerland AG 2019

\section{Correction to: Aquatic Sciences (2019) 81:24} https://doi.org/10.1007/s00027-019-0622-7

In the original publication, the subscript number 2 were incorrectly added without the subscript format as ' $\mathrm{CO} 2$ ' and 'O2' in Figs. 4 and 5 legends. The correct figure legends are given here.

Fig. 4 Atmospheric fluxes of $\mathrm{CO}_{2}$ and $\mathrm{O}_{2}$ with the lake water. Average diel flux rates of $\mathrm{CO}_{2}(\mathbf{a})$ and $\mathrm{O}_{2}(\mathbf{b})$ May 30th-June 9th 2016. During this time of early summer the $\mathrm{CO}_{2}$ flux is constantly positive from the atmosphere to the lake water. The oxygen flux varies from a nocturnal inward flux from the atmosphere to the lake water (above the dotted line) and an outward flux during the day. Dashed lines are $95 \%$ confidence intervals.
The original article can be found online at https://doi.org/10.1007/ s00027-019-0622-7.

Mikkel René Andersen

mikkel.andersen@dkit.ie

1 Centre for Freshwater and Environmental Studies, Dundalk institute of Technology, Dundalk, Ireland

2 Freshwater Biological Section, University of Copenhagen, Copenhagen, Denmark
Fig. 5 Relationships between daily NEP $\mathrm{O}_{2}$, NEP DIC and DIC removal. a $\mathrm{NEP}_{\text {day }} \mathrm{O}_{2}$ vs. $\mathrm{NEP}_{\text {day }}$ DIC; $\mathrm{y}=0.97 \mathrm{x}$ $-7.5, \mathrm{n}=29, \mathrm{R}^{2}=0.75$. b $\mathrm{NEP}_{\text {day }} \mathrm{O}_{2}$ vs. DIC removal: $\mathrm{y}=0.65 \mathrm{x}-8.3, \mathrm{n}=29, \mathrm{R}^{2}=0.59$. $\mathrm{c} \mathrm{NEP}_{\text {day }}$ DIC vs. DIC removal, $\mathrm{y}=0.69 \mathrm{x}-2.8, \mathrm{n}=29, \mathrm{R}^{2}=0.84$. The dotted lines are the fitted slopes of linear regressions, the dashed lines are the $1: 1$ lines.

Publisher's Note Springer Nature remains neutral with regard to jurisdictional claims in published maps and institutional affiliations. 